\title{
On uneven internationalisation, disciplinary diversity and interpretation of co-citation analysis
}

Asya Pisarevskaya ${ }^{*}$, Nathan Levy 10 and Peter Scholten

* Correspondence: pisarevskaya@ essb.eur.nl

Department of Public Administration and Sociology, Erasmus University Rotterdam Rotterdam, The Netherlands

\begin{abstract}
In this rejoinder for this special issue, we enter into dialogue with the various commentaries that our article "Between Fragmentation and Institutionalisation" received. In doing so, we address some of the commonly-identified limitations of our paper and clarify the interpretation of some of our findings. This includes key issues such as the uneven internationalisation of migration studies, the need to reveal a broader variety of disciplinary contributions to the field, and the need for some further clarification of the results of the co-citation analysis and caveats of its interpretation.
\end{abstract}

\section{Introduction}

We thank the various contributors to this special issue of CMS for their commentaries on our paper 'Between fragmentation and institutionalization.' It has been very inspiring to reflect further (also at a special session in Lisbon in February 2020) about the development of our research field, and on the state of our field as shown in our analysis. We hope that this will contribute to a more reflexive development of the field around some of the core issues identified by this series.

In this rejoinder, we will respond to most of the comments that we have received. We will certainly not be able to answer everything that has come up, and in some cases more research will be required. However, we would like to single out some key points and respond to these in more detail. This includes the uneven internationalisation of migration studies, the need to reveal a broader variety of disciplinary contributions to the field, and the need for some further clarification of the results of the co-citation analysis and caveats of its interpretation.

\section{On uneven internationalisation}

Several commentators rightly note that one of the key concerns in the development of migration studies is the uneven internationalisation of knowledge production. We are happy that our article has helped illustrating how uneven it has really been. However, several commentators argue that we could have gone further, and noted the overall

(c) The Author(s). 2020 Open Access This article is licensed under a Creative Commons Attribution 4.0 International License, which permits use, sharing, adaptation, distribution and reproduction in any medium or format, as long as you give appropriate credit to the original author(s) and the source, provide a link to the Creative Commons licence, and indicate if changes were made. The images or other third party material in this article are included in the article's Creative Commons licence, unless indicated otherwise in a credit line to the material. If material is not included in the article's Creative Commons licence and your intended use is not permitted by statutory regulation or exceeds the permitted use, you will need to obtain permission directly from the copyright holder. To view a copy of this licence, visit http://creativecommons.org/licenses/by/4.0/. 
Anglo-American centricity of the findings we presented. This particularly involves the invisibility of migration research from the regions of Asia, Africa and Latin America in our study. While it was not our intention to exclude any of these regions from the analysis of the field, it is true that our data collection approach, via an English-language search query of the Web of Science (WoS) database, resulted in such a bias. As DeWind (2020) rightly pointed, we, as researchers, are often limited only to our part of the "elephant", when trying to grasp the extent of knowledge production in this tremendously expanded field. This general bias is also present in our everyday practices of conducting literature reviews and publishing, in which we often refer to publications that are written in the language(s) we publish in or read. It is clear there is much more relevant research out there than we cite in our paper, also given the word limit, in languages we do not know, or published in the journals that are not considered high quality (in terms of inclusion in the WoS database).

Being aware of the language limitations of our data collection, we indeed expected that the papers produced by the authors writing in English would be overrepresented in our analysis. We knew that because of that, it would be impossible to rightly assess the amount of research produced in the countries and regions where the main language of scientific publishing is, for instance, Chinese, French, Russian, Spanish or any other. That is why we did not aim to compare countries and regions in terms of the amount of their overall output and the importance of their scientific contributions. In the analysis of internationalisation in the field of migration studies, we compared the change in the numbers of international collaborations over time. Figure 6 (Levy et al. 2020a, 2020b) clearly shows that the amount of international co-authorships in Englishlanguage publications significantly increased between 1998 and 2018. We expect that this is a general world-wide trend, which would also be observed in publications written in other languages in countries where those languages are spoken, however this is yet to be proved.

We acknowledge the argument by Chan (2020), who pointed out that Asian scholarship on migration has not been portrayed in all its richness and variety of theoretical contributions. Nevertheless, even with the aforementioned limitations of data and highly probable underrepresentation of overall research output in this region, our analysis of internationalisation still demonstrated that the proclivity of scholars based in Asia to co-author internationally is comparatively high, with most of the research conducted in the countries where the important centres of migration research have been established. DeWind (2020) suggested in his commentary that many "immigrant scholars" from other regions, and especially from Asia, have studied in the US and advanced the field of migration research by investigating immigrant communities from the position of an "insider". Probably some of these scholars returned to their countries of origin and continued working on migration, as well as maintaining connections with colleagues abroad. As Chan pointed out (2020), Asian scholars gave additional readership to many English-language publications on migration and advanced exploration of 'south-south migration' along with many other topics related to internal migration and gender and migration nexus (cf. Kofman 2020).

It is true that in the co-citation analysis we did not find a specific cluster of Asian scholarship separate from the rest. However, the names mentioned by Chan (2020) are indeed embedded in several reference networks. For instance, in the period 2004-2015 
H.Z. Wang, S. Huang and B. Yeoh are located in the "Global systems school" cluster, while M. Lu is part of "Michigan-Wisconsin School", meaning that their works are often cited together with authors from these clusters. Moreover there are many more Asian scholars in the co-citation networks but we did not trace the geography of their institutional affiliations in this particular analysis, ${ }^{1}$ and therefore, we do not have enough evidence to demonstrate the amount or prominence of their scholarly work and the co-citation links with authors from other regions of the world.

The same argument applies to scholars from other regions. The absence of separate clusters indicating the regional focus of authors should not be interpreted as a lack of conceptual importance of this region in migration studies, because what the clusters show is the separateness of epistemic communities, not the importance. The number of citations indeed could point at the prominence of specific authors in the field, however, since our data has limitations, perhaps the citation count of authors that mainly publish in non-English language literature is not fully accounted for. To conclude, we restate that the co-citation networks of authors in our paper were not analysed in terms of their geographical spread or institutional affiliations. It would be an interesting topic for future analyses to explore patterns of internationalisation in the citation behaviour of migration researchers. Moreover, we acknowledge that for such an analysis, bibliometric data with a wider linguistic coverage should be used.

\section{On the disciplinary diversity of migration studies}

Another theme discussed in this commentary series was the disciplinary diversity of migration studies. Our analysis helps to understand the growing interdisciplinarity of the field. However, commentators also point at the failure of our analysis to accurately capture the prominence and contribution of every discipline. We agree with the authors that in order to advance interdisciplinary research on migration we need to be aware of various disciplinary perspectives in migration studies and their unique conceptual and methodological traditions and innovations. Hollifield (2020), King (2020) and Vertovec (2020) provided valuable additions for such an overview, diving into thematic angles of several disciplines and mentioning prominent authors that we have not pointed out.

Furthermore, echoing DeWind's elephant analogy mentioned previously, our disciplinary orientation (based in a Department of Public Administration and Sociology at Erasmus University Rotterdam) may have acted as an heuristic torch illuminating familiar authors in the co-citation maps more strongly than others, despite our triangulation between what the interviewees said, which authors the maps highlighted, and those authors with most prominent publications. Indeed, our expert interviewees also mentioned primarily those disciplines in migration studies as important in which they either work or have worked themselves, or those with whose contributions they have been familiar. Nobody on their own was able to provide comprehensive overview of the disciplinary variety of migration research; only by bringing individual accounts together a bigger picture emerges.

${ }^{1}$ The only information a co-citation analysis can unveil is authorship, and, where relevant, title and year of publication. 
Our study did not intend to provide such a comprehensive overview, or to compare the strength of disciplinary contributions to the field. To clarify, although the interviews gave us a feel for what to expect, we did not know what kind of epistemic communities we would be able to identify via co-citation analysis. What would the network clusters indicate: authors grouped by country, region, theme, theory, discipline or even method? During the interpretation of the networks we looked at the centre of each cluster and used the insights from the interviews to understand the nature of the clustering. There, some indication of disciplinary divides emerged. There are probably several reasons why historians, anthropologists, and geographers did not form their own separate clusters in the citation networks. For example, as King rightly presumed, one of the reasons could be that "geographers" worked across disciplines and consequently their works were studied and cited by many non-geographers. This would lead to geographers being spread across the entire co-citation map. As we see, from the authors King mentions, in the period 2005-2014, Skeldon is often cited with authors from cluster "Global Systems school", while Boyle and Ravenstein are cited more often with those in the "Michigan-Wisconsin school".

\section{Missing topics and co-citation analysis}

To conclude this rejoinder, we address some of the other more minor critiques from the series besides those on uneven internationalisation and the disciplinary make-up of migration studies. On King's observation that we do not discuss internal or domestic migration. Rather than an IMISCOE orientation, this derived from the fact that we simply did not identify an internal migration community in the co-citation analyses (for similar reasons to those noted above about certain disciplines). That said, literature on internal migration was present in our dataset, since all titles that contained "*migra"" on WoS, from the social sciences and humanities, were included. Likewise, while historically part of the vernacular of IMISCOE work, the terminology used to describe certain phenomena (acculturation, integration, etc.) was not used normatively but descriptively, in relation to the work of the authors who appeared in those clusters, and the terms often noted in the titles of their publications. We acknowledge the potential "straitjacket" that these concepts may impose on "how we think about migration" (King 2020), however, we cannot erase them from history of migration studies.

Secondly, we address some of the other apparent thematic omissions from our study. King (2020) and Kofman (2020) observe an apparent omittance of refugee studies and gender \& migration. In their respective views, these are two important epistemic communities in migration studies. We agree. Perhaps more clearly than anything else, the co-citation analysis shows the disciplines and concepts that structure citation communities in the field. But it is rather more difficult to find thematic clusters; refugee studies scholars, or gender scholars may indeed be found among the sociologists, the economists, the global systems scholars, and so on. While the article opening this series focused on authors and countries, our previous work (see Pisarevskaya et al. 2019) entailed a large-scale analysis of topics and themes in migration studies. That article, it ought to be added, highlighted the growing prominence of research on refugees (post2015) and research on gender (since 2000) in migration studies. Vertovec also remarks on the apparent omission of transnationalism. Those who have been involved in the 
development of this concept are found in the "Global Systems school" cluster, which we labelled as such due to its broader conceptual scope.

Hollifield (2020) observed that we lacked discussion of the politicisation of migration. Similarly, Vertovec's (2020) third cheer was lacking because of the field's failure, broadly speaking, to satisfactorily inform public opinion and influence policymaking. While such discussion was beyond the scope of the bibliometric analysis - it is hard to measure such influences with the data we had - these comments do indeed raise interesting questions in terms of the relationships of research and policy. For instance, policy questions in the US, as DeWind (2020) noted, and EU institutions and politics have been stimuli in the development of the field. Policy agendas have certainly influenced research, and migration research is to some extent intended to influence policy making. But not all migration research is. Not all migration scholars apply for national government or EU funding; some avoid it. This may create a split in the research field, in which some scholars are more theory-driven, while others are more policy-oriented. Our paper did not discuss this divide, and perhaps indeed overlooked it. Nonetheless, future researchers may make use of our data in the Harvard Dataverse (Levy et al. 2020b) in the context of a deductive study of this nature.

Of course, in closing this rejoinder, perhaps it is appropriate to return to the question of institutionalisation in migration studies that our opening article raised itself. As DeWind has already done, both in this series (DeWind 2020) and in an earlier roundtable discussion (IMISCOE 2020), perhaps it is, moreover, appropriate to question the question itself. Is institutionalisation necessarily a 'good thing'; doesn't the institutionalisation of migration studies really mean homogenisation? While our research over the past 2 years (Levy et al. 2020a, 2020b; Pisarevskaya et al. 2019; Levy 2020) indicates that it has not meant homogenisation, this risk still remains. Commentary series such as this one and its predecessors offer a stimulus for critical reflection on migration studies and, though a small contribution to this enormous field, the chance to mitigate and minimize that risk.

\section{Acknowledgements}

We would like to thank all participants of the commentary series and roundtable discussion at the CrossMigration closing conference in Lisbon in February 2020 for their contributions to developing our thoughts on this topic.

Authors' contributions

All authors met to discuss which aspects of the commentary series to highlight in the rejoinder. AP drafted the main text. NL cross-checked and edited, making some additions to the final section. PS edited and further refined some of the responses. AP produced a final draft which was cross-checked and approved by all authors.

\section{Funding}

This series emerged from the CrossMigration project funded by the EU Horizon 2020 programme under grant agreement Ares (2017) 5627812-77012.

Website: migrationresearch.com.

Availability of data and materials

N/A (Please refer to opening article in series).

Competing interests

The authors declare that they have no competing interests.

Received: 29 May 2020 Accepted: 5 July 2020

Published online: 03 October 2020

References

Chan, Y. W. (2020). Asian perspectives of migration: a commentary. Comparative Migration Studies, 8. https://doi.org/10.1186/ s40878-020-00190-5. 
DeWind, J. (2020). Blind men and the elephant: one view of the field of migration studies. Comparative Migration Studies, 8. https://doi.org/10.1186/s40878-020-00191-4.

Hollifield, J. F. (2020). Is migration a unique field of study in social sciences? A response to Levy, Pisarevskaya, and Scholten. Comparative Migration Studies, 8. https://doi.org/10.1186/s40878-020-00192-3.

IMISCOE (2020). Roundtable: Innovative science-society dialogues on migration: Opening Plenary at the Conference "The coming of age of migration studies Debating the evolution and impact of a research field". Retrieved from https:// migrationresearch.com/posts/roundtable-innovative-science-society-dialogues-migration.

King, R. (2020). On migration, geography, and epistemic communities. Comparative Migration Studies, 8. https://doi.org/10. 1186/s40878-020-00193-2.

Kofman, E. (2020). Unequal internationalisation and the emergence of a new epistemic community: gender and migration. Comparative Migration Studies, 8. https://doi.org/10.1186/s40878-020-00194-1.

Levy, N. (2020). An IMISCOE effect? The role of a network of excellence in developing European migration research in the twenty-first century. Comparative Migration Studies, 8. https://doi.org/10.1186/s40878-020-00196-z.

Levy, N., Pisarevskaya, A., \& Scholten, P. (2020a). Between fragmentation and institutionalisation: the rise of migration studies as a research field. Comparative Migration Studies, 8. https://doi.org/10.1186/s40878-020-00180-7.

Levy, N., Pisarevskaya, A., \& Scholten, P. (2020b). Between the fragmentation and institutionalisation of migration studies: VOSViewer map and network data. Harvard Dataverse. https://doi.org/10.7910/DVN/NNKOCQ. Accessed 28 May 2020.

Pisarevskaya, A., Levy, N., Scholten, P., \& Jansen, J. (2019). Mapping migration studies: An empirical analysis of the coming of age of a research field. Migration Studies. Advance online publication. https://doi.org/10.1093/migration/mnz031.

Vertovec, S. (2020). Two cheers for migration studies. Comparative Migration Studies, 8. https://doi.org/10.1186/s40878-02000195-0.

\section{Publisher's Note}

Springer Nature remains neutral with regard to jurisdictional claims in published maps and institutional affiliations.

\section{Submit your manuscript to a SpringerOpen ${ }^{\circ}$ journal and benefit from:}

- Convenient online submission

- Rigorous peer review

- Open access: articles freely available online

High visibility within the field

Retaining the copyright to your article

Submit your next manuscript at $\boldsymbol{\sim}$ springeropen.com 